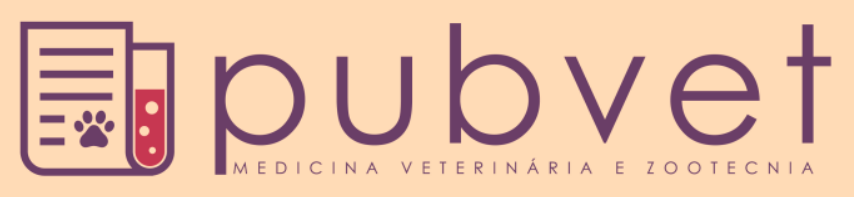

https://doi.org/10.31533/pubvet.v12n9a172.1-3

\title{
Fístula Infraorbitária em felino: Relato de caso
}

\section{Laura Ruschel Cattani ${ }^{\bullet}$, Lúcia Dal Santo ${ }^{\bullet}$, João Victor Schwerz ${ }^{\bullet}$, Natieli Caroline Ferro ${ }^{\circ}$}

Universidade de passo fundo, Faculdade de agronomia e medicina veterinária, Curso de medicina veterinária Autor para correspondência, E-mail: melhoramigoplazapet@gmail.com

\begin{abstract}
RESUMO. Dentre as várias afecções orais que acometem os felinos, podemos destacar a fístula infraorbitária, que consiste em uma lesão osteolítica periapical (osteólise causada por inflamação decorrente da necrose pulpar e contaminação bacteriana do canal radicular) geralmente no dente. No exame clínico do animal constatou-se a presença de fístula infraorbitária com alteração no dente quarto pré-molar. Como tratamento foi realizado a técnica de exodontia associada à administração de antimicrobianos e anti-inflamatórios no pré-operatório, e antimicrobianos e analgésicos no pós-operatório.
\end{abstract}

Palavras chave: Fístula infraorbitária, exodontia, felinos.

\section{Infraorbital fistula in feline: case report}

ABSTRACT. Among the various oral affections that affect the felines, we can highlight the infraorbital fistula, which consists of a periapical osteolytic lesion (osteolysis caused by inflammation due to pulpal necrosis and bacterial contamination of the root canal), usually in the tooth. In the clinical examination of the animal the presence of infraorbital fistula with alteration in the fourth premolar tooth was verified. As a treatment, the Exodontia technique associated with the administration of antimicrobials and antiinflammatories in the pre-operative period, and antimicrobials and analgesics in the posoperative period were performed.

Keywords: Infraorbitary fistula, exodontia, felines

\section{Fístula Infraorbitária em felino: relato de caso}

RESUMEN. Entre las diversas afecciones orales que afectan a los felinos, podemos destacar la fístula infraorbitaria, que consiste en una lesión osteolítica periapical (osteolisis causada por inflamación derivada de la necrosis pulpar y contaminación bacteriana del canal radicular) generalmente en el diente. En el examen clínico del animal se constató la presencia de fístula infraorbitaria con alteración en el cuarto premolar. Como tratamiento se realizó la técnica de Exodoncia asociada a la administración de antimicrobianos y antinflamatorios en el preoperatorio, y antimicrobianos y analgésicos en el postoperatorio.

Palabras clave: Fístula infraorbitaria, exodoncia, felinos

\section{Introdução}

A saúde oral dos animais está relacionada ao aumento da expectativa de vida, uma vez que as patologias orais podem interferir na saúde geral do paciente (Dias et al., 2011). Dentre as afecções orais que podem acometer os felinos,pode-se destacar a fístula infraorbitária, que consiste em uma lesão osteolítica periapical (osteólise causada por inflamação decorrente da necrose pulpar e contaminação bacteriana do canal radicular) geralmente no dente quarto pré- molar superior ( $\left.4^{\circ} \mathrm{PMS}\right)$ (Gioso, 2003). 
Para um bom diagnóstico é necessária uma anamnese minuciosa da cavidade oral e exames complementares como o exame radiológico. A exodontia é considerada umas das intervenções cirúrgicas mais frequentes na clínica de cães e gatos, sendo a afecção periodontal severa, com mobilidade dentária, uma das indicações deste procedimento (Gioso, 2003).

O presente trabalho tem como objetivo relatar o caso clínico de fístula infraorbitária em um felino e o procedimento aplicado.

\section{Relato de caso}

Foi atendido no Hospital Veterinária da UPF um felino, encaminhado para cirurgia com o diagnóstico de fístula infraorbitária com alteração no dente quarto pré-molar superior direito e com presença de doença periodontal inicial (Figura 1).

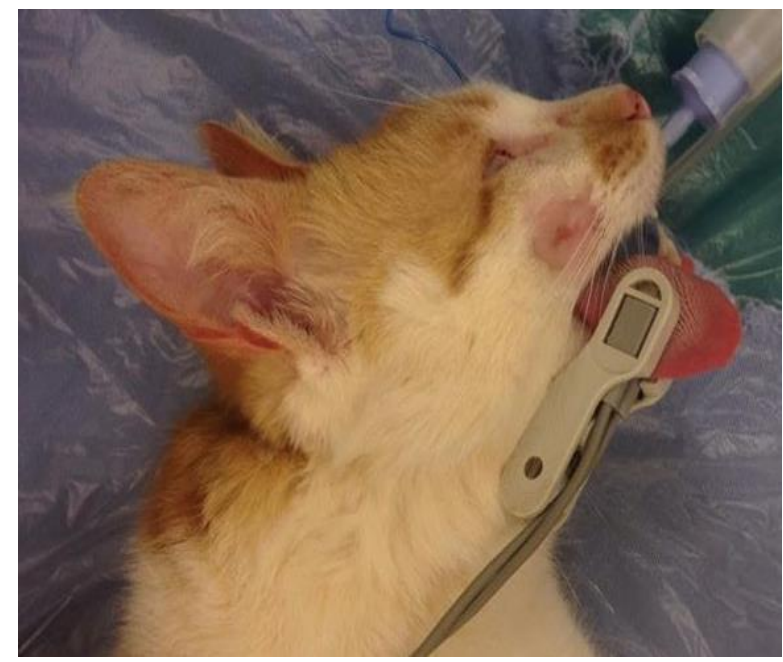

Figura 1. Lesão cutânea na região infraorbitária esquerda.

No pré-operatório administrou-se meloxicam $(0,05 \mathrm{mg} / \mathrm{kg}$ durante 3 dias $)$ e antibiótico a base de metronidazol e espiramicina $(1 \mathrm{mg} / \mathrm{kg}$ durante 7 dias). Foi realizada tricotomia 10 minutos antes, ao redor da fístula e cavidade oral. As medicações pré-anestésicas usadas foram zoletil (4 mg/kg IM) e tramadol ( $2 \mathrm{mg} / \mathrm{kg} \mathrm{IM})$, seguido da indução com propofol (4 mg/kg IV) e manutenção com isofluorano volátil. Também foi realizada a anestesia regional com bloqueio maxilar usando Lidocaína $(0,5 \mathrm{~mL})$. O animal foi colocado em decúbito lateral esquerdo, e durante todo o procedimento cirúrgico recebeu fluidoterapia intravenosa $\mathrm{NaCl} 0,9 \%(10 \mathrm{~mL} / \mathrm{kg} / \mathrm{h})$.

Fez-se a antissepsia prévia e definitiva da mucosa oral com clorexidine aquoso 0,2\%. Foi realizada então sindesmotomia, luxando-se todas as raízes do $4^{\circ} \mathrm{PMS}$ e em seguida a exodontia do mesmo. Foi necessário também a realização da sindesmotomia e exodontia do $1^{\circ} \mathrm{MS}$, e a curetagem do canino superior, pois possuíam alterações e doença periodontal inicial.

Com uma sonda foi derramado solução fisiológica $0,9 \%$ + iodo $0,25 \%$ dentro da cavidade da extração do $4^{\circ} \mathrm{PMS}$. Em seguida realizou-se a restauração da mucosa e a síntese com fio absorvível e sutura de PIS (Figura 2).

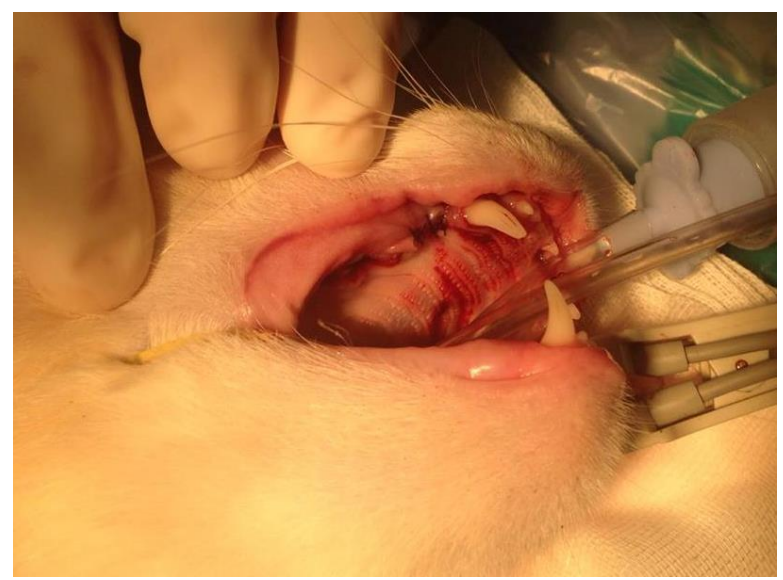

Figura 2. Exodontia do $4^{\circ} \mathrm{PMS}$ e $1^{\circ} \mathrm{MS}$

Para o pós-operatório as indicações feitas foram antibiótico a base de metronidazol e espiramicina ( $1 \mathrm{mg} / \mathrm{kg}$ durante 7 dias), meloxicam $(0,5 \mathrm{mg} / \mathrm{kg}$ durante 3 dias $)$, tramadol $(2-3 \mathrm{mg} / \mathrm{kg}$ durante 3 dias) associado a dipirona $(25 \mathrm{mg} / \mathrm{kg}$ SID ou $12,5 \mathrm{mg} / \mathrm{kg}$ BID durante 3 dias). Outra indicação foi o uso de alimentação pastosa até ocorrer à cicatrização, a qual será feita por segunda intenção.

\section{Discussão}

A fístula infraorbitária, também conhecida como fístula do "carniceiro", é uma lesão osteolítica periapical do quarto pré-molar superior (4 PMS) (Gioso, 2003). Este dente, cuja função é auxiliar na dilaceração de alimentos, está localizado distalmente ao terceiro pré-molar e medialmente ao primeiro molar (Holmstrom, 1995). Possui três raízes (trirradicular) inseridas no osso maxilar, próximas à região infraorbitária direita e esquerda dos cães e gatos (Wiggs \& Lobprise, 1997).

Ocasionalmente, esta condição pode afetar o primeiro molar superior ou o primeiro molar inferior (Harvey et al., 2004). Clinicamente, a doença é observada como inchaço abaixo da região medial do olho. Os dentes afetados podem estar fraturados ou apresentar bolsas periodontais profundas e evidentes. No entanto, em muitos 
casos o dente está clinicamente normal (Harvey et al., 2004). Estes sinais clínicos geralmente são uma exacerbação aguda de uma condição crônica e não é considerada uma emergência cirúrgica. No entanto, o tratamento dentário é necessário para eliminar a causa de base da lesão (Harvey \& Emily, 1993).

Corroborando com o relato de Gonzaga (2006) e Aylon (2008), o diagnóstico diferencial da fístula infraorbitária deve ser baseado em ferida cutânea por traumatismos ou dermatopatias, recidivantes após a administração prolongada de antibióticos. Pela localização da lesão dentária, torna-se imprescindível a realização de exame radiográfico, pois o fato da lesão não estar macroscopicamente perceptível, não significa que endodonticamente não esteja se desenvolvendo (Aylon, 2008).

De acordo com Leon-Roman \& Gioso (2004), a exodontia é uma intervenção cirúrgica odontológica comumente utilizada em clínica de pequenos animais, principalmente em casos onde o tratamento endodôntico não foi satisfatório ou por opção do proprietário, devido aos menores custos desse procedimento.

O prognóstico da fístula infraorbitária é favorável desde que o diagnóstico seja preciso e o tratamento adequado (Birchard \& Sherding, 2008).

\section{Considerações Finais}

Atualmente, o médico veterinário tem como desafio mostrar aos proprietários a importância dos exames periódicos da cavidade oral e da higienização bucal de seus animais, com intuito de melhorar a qualidade de vida dos mesmos.

Os tratamentos disponíveis para animais com fístula infraorbitária incluem a exodontia (extração dentária) ou a endodontia (tratamento de canal), associadas à administração de antimicrobianos e anti-inflamatórios no pré e pósoperatório, tendo assim um prognóstico favorável.

\section{Referências Bibliográficas}

Aylon, E. G. 2008. Lesão periapical do quarto pré- molar superior esquerdo com formação de fístula: relato de caso. Master of Science, ANCLIVEPA - SP, São Paulo, Brasil.

Birchard, S. J., \& Sherding, R. G. 2008. Manual Saunders: clínica de pequenos animais (Vol. 3). São Paulo.

Dias, F. G., Vianna, G. D., Paula, T. M., \& Dias, L. 2011. Fístula infraorbitária em cão - Relato de caso. Revista Científica Eletrônica de Medicina Veterinária, 16, 1-13.

Gioso, M. A. 2003. Odontologia para o clínico de pequenos animais (5a ed. Vol. 15). São Paulo, São Paulo, Brasil: Leditora.

Gonzaga, P. O. 2006. Tratamento endodôntico em pequenos animais. 2006. 57f. Master of Science, Universidade Castelo Branco, São Paulo.

Harvey, C. E., \& Emily, P. 1993. Small animal dentistry. St. Louis: Mosby.

Harvey, R. G., Harari, J., \& Delaauche, A. J. 2004. Doenças do ouvido em cães e gatos. Rio de Janeiro: Revinter, 1, 35-41.

Holmstrom, S. E. 1995. Canine oral diagnosis. In D. A. Crosley \& S. Penmann (Eds.), Manual of small animal dentistry (pp. 114-128): Gloucestershire: British small animal veterinary association.

Leon-Roman, M. A., \& Gioso, M. A. 2004. Endodontia-anatomia, fisiopatologia e terapia para afecções dos tecidos internos do dente. Revista Científica de Medicina Veterinária Pequenos Animais e Animais de Estimação, 2(7), 195-203.

Wiggs, R. B., \& Lobprise, H. B. 1997. Veterinary Dentistry: principles and practice: LippincottRaven Publishers.

Recebido: 17 Nov., 2017 Aprovado: 5 Jan. 2018
Publicado: 31 Ago. 2018

Licenciamento: Este artigo é publicado na modalidade Acesso Aberto sob a licença Creative Commons Atribuição 4.0 (CC-BY 4.0), a qual permite uso irrestrito, distribuição, reprodução em qualquer meio, desde
que o autor $\mathrm{e}$ a fonte sejam devidamente creditados. 